\title{
A Biologically Inspired Technique for Sampling of Color Images
}

\author{
Rajesh B Raut \\ Assistant Professor \\ Shri Ramdeobaba Kamla Nehru \\ Engg College, Nagpur \\ $+91-712-2582844$ \\ rautrb@rknec.edu
}

\author{
Dr. K.M. Bhurchandi \\ Professor \\ Shri Ramdeobaba Kamla Nehru \\ Engg College, Nagpur \\ $+91-712-2582844$ \\ bhurchandikm@rknec.edu
}

\begin{abstract}
Color space dimensionality possesses main problem in fast processing of color images so appropriate sampling of color images is very important. Unlike the existing statistical sampling algorithm, in this paper, a biologically inspired non-linear color image sampling technique has been proposed using non-uniform quantization of RGB space. Response of human retinal receptors to various light intensities is non-linear in nature. Buschbaum has qualitatively presented the non-linear tan-sigmoid model of the human vision as against the logarithmic and power law models. An experiment has been carried out on certified normal color vision observers in broad day light conditions to model their color vision. Readings of this experiment were used to compute the parameters of Red, Green and Blue color vision non-linearity presented by Buchsbaum. These parametric non-linearity equations were used to sample the color images and other applications of the work have been proposed. The non-linearity equations with respective parameters represent the models of Red, Green and Blue color vision receptors. Physiological limitations and facts of human vision have been utilized to compute the parameter.
\end{abstract}

\section{Keywords}

Non-linear sampling, Human retinal receptors, Buchsbaum nonlinearity, Just Noticeable Difference (JND), Model of color vision.

\section{INTRODUCTION}

Buchsbaum presented a mathematical model of visual nonlinearity on the basis of signal detection theory and neural activities behind human vision [7]. Continuing this work, Buchsbaum further presented a model of human retina for color vision in the context of different color vision theories and signal detection theory [8]. But no consideration was given to computation of the parameters of the proposed non-linearity. Computation of parameters of the non-linearity forms the core part of this work. It has been predicted that individual color

Permission to make digital or hard copies of all or part of this work for personal or classroom use is granted without fee provided that copies are not made or distributed for profit or commercial advantage and that copies bear this notice and the full citation on the first page. To copy otherwise, or republish, to post on servers or to redistribute to lists, requires prior specific permission and/or a fee.

Bionetics'08, Nov 25-28, 2008, Hyogo, Japan.

Copyright 2008 ICST 978-963-9799-35-6 receptor also has the similar non-linear characteristics [9]. All the color receptors of similar type have the similar characteristic but they may be excited to varying extents as predicted by Gaurav Sharma [1] by the varying illumination all over the retina. And thus a reasonably accurate average model of each type of receptor can be proposed based on this physiological fact. These parameters were initially computed assuming uniform light intensity distribution over the scene by A. K. Ray, K. M. Bhurchandi [12]. However this may not be always true in real life situations. Sampling of color images using statistical technique has been presented in $[2,3,4,5,11]$. Color segmentation based on the power law inspired 'Just Not Similar' (JNS) measure was presented in $[13,14]$. A neural network was trained by E. Boldrin and Schettini [11] to find out self similar colors up to three 'just noticeable differences' (JND). Effect of chromatic illumination and the calibration to retrieve the original color was presented in $[4,6,11]$. HSI system is closer to human vision model; however most of the algorithms can be implemented using the RGB system at much lower computational cost. The sampling technique presented here can be easily ported to other color spaces.

In this paper, a procedure for obtaining the discrimination response of certified color normal observers have been formulated. A neural network based procedure has been formulated for calculating the parameters of the non-linearity using the response data obtained from the observers' response. The experimentation carried out for this work has been described further in this paper.

The organization of the paper is as follows: Section 2 describes the physiological limitation of human eye. Buchsbaum non-linear model of human eye is presented in section 3. An experiment has been carried out to register the just noticeable different color response of a sound color normal eye to the varying color intensities in the three basic colors in section 4. Section 5 describes the neural network model to fit the nonlinearity along with the computed parameters. Based on this parametric nonlinearity, the RGB space has been sampled and the same approach can be used for computer vision applications. The responses of the color normal eyes have been registered under broad day light vision to model the R, G and B non-linearity. The response of the color normal eyes can be registered under different illumination conditions which will obviously results in the set of different parameters for different illumination intensities for the same nonlinearity equation. To sum up some color image sampling results are provided in section 6 for the sake of completeness. 


\section{PHYSIOLOGICAL LIMITATIONS OF HUMAN EYE AND VISION}

The three types of cones in human retina viz, Red, Green and Blue respond to specific ranges of wavelengths corresponding to the three basic colors Red, Green and Blue. According to the threecolor theory of Thomas Young [1,7,9,10], all other colors are perceived as linear combinations of these basic colors. According to A. C. Guyton [9] a normal human eye can perceive at the most 17,000 colors at maximum intensity without saturating the human eye. In other words, if the huge color space is sampled in only 17,000 colors, a performance matching close to human vision at normal illumination may be obtained. A human eye can discriminate between two colors if they are at least one 'just noticeable difference' away from each other [1,7,9]. The actual value of the just noticeable difference in terms of color coordinates may not be constant over the complete RGB space due to non-linearity of human vision and the non-uniformity of the RGB space.

Further, from the physiological knowledge, the red cones in the human retina are least sensitive, blue cones are moderately sensitive and the green cones are most sensitive [9]. Keeping this physiological fact in mind, the red axis has been quantized in 24 levels and the blue and green axes are quantized in 26 and 28 levels. The $24 \times 26 \times 28$ quantization in the RGB space results in slight over-sampling (17,472 different colors) but it ensures that each of the 17,000 colors is accommodated in the sampled space.

\section{BUCHSBAUM NONLINEARITY}

The incremental behavior of human retina has been modeled using a differential equation as presented in equation (1a).

$\sqrt{K} \frac{d y(I)}{d I}=\frac{\sqrt{y(I)}}{w I}$

$K$ represents gain, $w$ is webber's fraction, $I$ input intensity and $y$ is output of the system.

As predicted by Buchsbaum, this incremental non-linear saturation behavior (response) of human vision can be represented by solution of equation (1a) considering incremental change in $I$ i.e. $\Delta I$ as a second order polynomial i.e. $\Delta I=\Delta I_{o}+p I+q I^{2}$, And it is observed at higher illumination intensities that $y(I)$ is a higher order function of the input intensity and it can be modeled by equation (1b).

$y(I)=\frac{K}{\sqrt{4 q+p^{2}}}\left[\tan ^{-1} \frac{2 q I+p}{\sqrt{4 q-p^{2}}}\right]^{2}+C$

The parameters p, q, $\mathrm{K}$ and $\mathrm{C}$ model the illumination and adoption conditions. It is obvious that the squared tansigmoidal function is able to model the saturation behavior of human vision at higherlevel intensities due to which at higher intensities the sensitivity of human eye reduces unlike logarithmic and power law models. Thus if equation (1b) represents the non-linear nature of a type of receptors, for example red cones, the response of each red cone should also be represented by equation (1b) with different parameters under following assumptions-

1) Every rod or cone receives the same proportion of illumination.

2) Illumination over the complete image is uniform.
These two assumptions lead to conclusion that, in such circumstances, the parameters $\mathrm{p}$ and $\mathrm{q}$ can be assumed constant. Equation (1b) is output function $\mathrm{y}(I)$ of the color vision system with color intensity $I$ as input variable. The aggregation of all individual sensor outputs is already modeled by equation (1b). Every rod and cone has got similar analytical transfer function as in equation (1b). Mathematically value of I can be computed from equation (2).

$$
I=\frac{\sqrt{4 q-p^{2}}}{2 q} * \tan \sqrt{\frac{(y-C) \sqrt{4 q+p^{2}}}{K}}-\frac{p}{2 q}
$$

The standard definition of the 'just noticeable difference' (JND) states that it is the minimum differential intensity input required to obtain the minimum visual differential output described in terms of real numbers i.e., starting from 1 in equation (1b). Thus after differentiating equation (1b) the equation (3) is obtained that models the discriminatory response of the human vision. But equation (3) is computationally more complex and is difficult to solve for I to find out the quantization levels on each axis corresponding to the respective just noticeable differences. Equation (2) presents the expression for I computed from equation (1b). However computation of I, by numerical differentiation of equation (1b) is computationally more efficient.

$$
\frac{d y(I)}{d I}=\frac{K\left(4 q-p^{2}\right)}{4 q+p^{2}} * \tan ^{-1} \frac{2 q I+p}{\sqrt{4 q-p^{2}}} \frac{1}{\left(1+p I+q I^{2}\right)}
$$

In the following section, an experimental procedure for computing the parameters $\mathrm{p}, \mathrm{q}, \mathrm{K}$ and $\mathrm{C}$ has been proposed. In this work the parameter $\mathrm{p}$ and $\mathrm{q}$ are not considered constant and are calculated using the proposed neural network. Based on this, models for Red, Blue and Green cones have been worked out and further a non-uniform color image quantization scheme has been presented. Similar procedure, involving three human color experts was used by E. Boldrin, R.Schettini [11] for first visually marking the noticeably different uniform texture colors on cloth and then subsequently to train a neural network for matching the cloth colors. And they were able to obtain the accuracy ranging from 2 to 6 color difference units as measured by colorimetric devices.

\section{THE EXPERIMENT}

An experiment has been carried out to register the just noticeable different color response of a sound color normal eye to the varying color intensities in the three basic colors. This response is further used to evaluate the parameters of the visual non-linearity. The incremental response procedure $[1,11]$ was used to record the response of an average eye. Color patches of size $5 \mathrm{~cm} \times 5 \mathrm{~cm}$ as in [11], and of varying intensities (with a step of intensity 4 in the range of intensity 0 to 255 levels) were prepared in each basic color ( $\mathrm{R}, \mathrm{G}$ and $\mathrm{B})$. A chamber illuminated by CIE standard daylight illuminant D65 can be used for the experiment to model observe the successive color shade palette of each basic color placed on an average gray background (to minimize the residual response of the eye) from a distance of $30 \mathrm{~cm}$ and asked to discriminate between successive color from each other.

The palette number (Plt. no.) in Table 1 implies the intensity range $4(\mathrm{i}-1)$ to $4 \mathrm{i}-1$ in which the response has been observed. For 
Table 1: A Typical Observation Table

\begin{tabular}{|c|c|c|c|c|c|c|c|c|c|c|c|c|c|c|c|}
\hline Plt. & jnd & jnd & jnd & Plt. & jnd & jnd & jnd & Plt. & jnd & jnd & jnd & Plt. & jnd & Jnd & Jnd \\
\hline No. & $\mathrm{R}$ & $\mathrm{G}$ & B & No. & $\mathrm{R}$ & $\mathrm{G}$ & B & No. & $\mathrm{R}$ & $\mathrm{G}$ & B & No. & $\mathrm{R}$ & $\mathrm{G}$ & B \\
\hline 1 & $Y$ & $\mathrm{~N}$ & $\mathrm{~N}$ & 17 & $\mathrm{~N}$ & $\mathrm{Y}$ & $\mathrm{Y}$ & 33 & $\mathrm{~N}$ & $\mathrm{~N}$ & $\mathrm{Y}$ & 49 & $\mathrm{~N}$ & $\mathrm{Y}$ & $\mathrm{Y}$ \\
\hline 2 & $\mathrm{~N}$ & $\mathrm{Y}$ & $\mathrm{Y}$ & 18 & $\mathrm{Y}$ & $\mathrm{Y}$ & $\mathrm{Y}$ & 34 & $Y$ & $\mathrm{Y}$ & $\mathrm{Y}$ & 50 & $Y$ & $\mathrm{Y}$ & $\mathrm{N}$ \\
\hline 3 & $\mathrm{Y}$ & $\mathrm{Y}$ & $\mathrm{N}$ & 19 & $\mathrm{~N}$ & $\mathrm{~N}$ & $\mathrm{~N}$ & 35 & $\mathrm{Y}$ & $Y$ & $\mathrm{Y}$ & 51 & $\mathrm{~N}$ & $\mathrm{Y}$ & $\mathrm{Y}$ \\
\hline 4 & $\mathrm{~N}$ & $\mathrm{Y}$ & $\mathrm{Y}$ & 20 & $\mathrm{Y}$ & $\mathrm{Y}$ & $\mathrm{Y}$ & 36 & $Y$ & $\mathrm{~N}$ & $\mathrm{Y}$ & 52 & $Y$ & $\mathrm{~N}$ & $Y$ \\
\hline 5 & $\mathrm{~N}$ & $\mathrm{Y}$ & $\mathrm{Y}$ & 21 & $\mathrm{Y}$ & $\mathrm{Y}$ & $\mathrm{Y}$ & 37 & $\mathrm{Y}$ & $\mathrm{Y}$ & $\mathrm{Y}$ & 53 & $\mathrm{~N}$ & $\mathrm{Y}$ & $\mathrm{Y}$ \\
\hline 6 & $\mathrm{Y}$ & $\mathrm{Y}$ & $\mathrm{N}$ & 22 & $\mathrm{Y}$ & $\mathrm{Y}$ & $\mathrm{N}$ & 38 & $\mathrm{Y}$ & $\mathrm{Y}$ & $\mathrm{Y}$ & 54 & $\mathrm{Y}$ & $Y$ & $\mathrm{Y}$ \\
\hline 7 & $Y$ & $\mathrm{~N}$ & $\mathrm{~N}$ & 23 & $\mathrm{Y}$ & $\mathrm{Y}$ & $\mathrm{Y}$ & 39 & $\mathrm{~N}$ & $\mathrm{~N}$ & $\mathrm{Y}$ & 55 & $\mathrm{Y}$ & $\mathrm{Y}$ & $Y$ \\
\hline 8 & $Y$ & $\mathrm{Y}$ & $\mathrm{Y}$ & 24 & $\mathrm{~N}$ & $\mathrm{~N}$ & $\mathrm{Y}$ & 40 & $\mathrm{Y}$ & $Y$ & $\mathrm{~N}$ & 56 & $\mathrm{~N}$ & $\mathrm{Y}$ & $Y$ \\
\hline 9 & $\mathrm{~N}$ & $\mathrm{Y}$ & $\mathrm{Y}$ & 25 & $\mathrm{Y}$ & $\mathrm{Y}$ & $\mathrm{Y}$ & 41 & $\mathrm{Y}$ & $\mathrm{Y}$ & $\mathrm{N}$ & 57 & $\mathrm{Y}$ & $\mathrm{N}$ & $\mathrm{N}$ \\
\hline 10 & $Y$ & $\bar{Y}$ & $\mathrm{Y}$ & 26 & $\mathrm{~N}$ & $\mathrm{Y}$ & $\mathrm{Y}$ & 42 & $\mathrm{Y}$ & $\mathrm{Y}$ & $\mathrm{Y}$ & 58 & $\mathrm{~N}$ & $\mathrm{Y}$ & $Y$ \\
\hline 11 & $Y$ & $\mathrm{~N}$ & $\mathrm{~N}$ & 27 & $\mathrm{Y}$ & $\mathrm{N}$ & $\mathrm{N}$ & 43 & $Y$ & $\mathrm{Y}$ & $\mathrm{N}$ & 59 & $\mathrm{~N}$ & $\mathrm{Y}$ & $Y$ \\
\hline 12 & $\mathrm{~N}$ & $\mathrm{Y}$ & $\mathrm{Y}$ & 28 & $\mathrm{Y}$ & $\mathrm{Y}$ & $\mathrm{Y}$ & 44 & $\mathrm{~N}$ & $\mathrm{~N}$ & $\mathrm{Y}$ & 60 & $\mathrm{~N}$ & $\mathrm{Y}$ & $\mathrm{N}$ \\
\hline 13 & $\mathrm{~N}$ & $\mathrm{~N}$ & $\mathrm{~N}$ & 29 & $\mathrm{Y}$ & $\mathrm{Y}$ & $\mathrm{Y}$ & 45 & $Y$ & $\mathrm{Y}$ & $\mathrm{Y}$ & 61 & $Y$ & $\mathrm{~N}$ & $Y$ \\
\hline 14 & $Y$ & $\mathrm{Y}$ & $\mathrm{Y}$ & 30 & $\mathrm{~N}$ & $\mathrm{Y}$ & $\mathrm{Y}$ & 46 & $\mathrm{~N}$ & $\mathrm{~N}$ & $\mathrm{Y}$ & 62 & $\mathrm{~N}$ & $\mathrm{Y}$ & $\mathrm{Y}$ \\
\hline 15 & $Y$ & $\mathrm{Y}$ & $\mathrm{N}$ & 31 & $\mathrm{Y}$ & $Y$ & $\mathrm{~N}$ & 47 & $Y$ & $\mathrm{Y}$ & $\mathrm{N}$ & 63 & $\mathrm{~N}$ & $\mathrm{Y}$ & $Y$ \\
\hline 16 & $Y$ & $\mathrm{~N}$ & $\mathrm{Y}$ & 32 & $\mathrm{Y}$ & $\mathrm{Y}$ & $\mathrm{Y}$ & 48 & $\mathrm{Y}$ & $Y$ & $\mathrm{Y}$ & 64 & $\mathrm{Y}$ & $\mathrm{Y}$ & $Y$ \\
\hline
\end{tabular}

example, for $\mathrm{i}=1$, the intensity range is 0 to 3 . The just noticeable difference or jnd values in each of $R, G$ and $B$ indicates the discriminability power of the observer between the successive palettes of colors. The jnd measure can assume either ' $\mathrm{Y}$ ' or ' $\mathrm{N}$ ' values. A ' $\mathrm{Y}$ ' indicates that a 'just noticeable difference' exists between the previously compared palette and the current one observed by the observer. Likewise ' $\mathrm{N}$ ' indicates that there does not exist any such 'just noticeable difference' between the previously compared palette and the current one. Thus an entry of ' $Y$ ' in the observation table increments the just noticeable difference counter and an ' $\mathrm{N}$ ' leaves the counter unchanged. The 'just noticeable difference' counter and the corresponding normalized color intensity values in the range 0 to 1 were used to fit the Buchsbaum's non-linearity. Thus three response measures have been obtained for the three basic colors for each human observer having sound vision. Here the response measure indicates the degree of discrimination that the observer can perceive between the two consecutive palettes of colors. This has been computed from the total ' $\mathrm{Y}^{\prime}$ count obtained from our experiment for each of the three colors. And further average $\mathrm{R}$ response, $\mathrm{G}$ response and $\mathrm{B}$ response were computed by averaging all the observer's respective responses. This yielded average $R, G$ and $\mathrm{B}$ responses of a sound human eye. A similar experiment was carried out by E. Boldrin [11] and they tried to provide a linear fit to their non-linear equation. The linear fits of the order from three to even thirty-eight were not sufficient to obtain the desired accuracy. In the next section, we derive a back-propagation algorithm for training the neural network to fit the visual nonlinearity i.e. to compute the parameters of equation (1b). In this neural network training approach, the maximum point error is ensured to be less than one JND besides minimizing the MSE for convergence. This neural network based computations give three sets of the parameters for the three types of receptors.

\section{NEURAL NETWORK FOR FITTING NON-LINEARITY}

Buchsbaum presented the non-linearity of vision in the parametric form as in equation (1). But nothing was said about computation of these parameters. This section presents a neural network for calculating the parameters of the non-linearity of human vision. As it's a continuous, monotonic and finite function of I, the nonlinearity itself can be used as transfer function of a single nonlinear neuron followed by a linear neuron as described latter in this section. The representation of equation (1b) has been modified as in equation (4) using algebraic manipulations. The weights $w 1, w 2, w 3$ and w4 are calculated using equation (5) to (8).

$$
\begin{aligned}
& y(I)=w_{3}\left[\tan ^{-1}\left(w_{1} * I+w_{2}\right)\right]^{2}+w_{4} \\
& w_{1}=\frac{2 q}{\sqrt{4 q-p^{2}}} \\
& w_{2}=\frac{p}{\sqrt{4 q-p^{2}}} \\
& w_{3}=\frac{K}{\sqrt{4 q+p^{2}}} \\
& w_{4}=C
\end{aligned}
$$

Thus the first neuron is a non-linear neuron while the second neuron is a linear neuron. The weights $w_{1}$ and $w_{2}$ are handled as biases and their weights may be upgraded appropriately using the derived back propagation weight upgrading formulae. Nearly $8,00,000$ iterations of the back-propagation algorithm were required to minimize the least squared error and at the same time bring down the maximum instantaneous error less than one just noticeable difference. The maximum error threshold was decided from the physiological knowledge of the human vision at less than a just noticeable difference. Thus the neural network in figure 1 
can be considered a model of a typical retinal receptor for uniform day-light illumination, after substituting the appropriate parameter values.

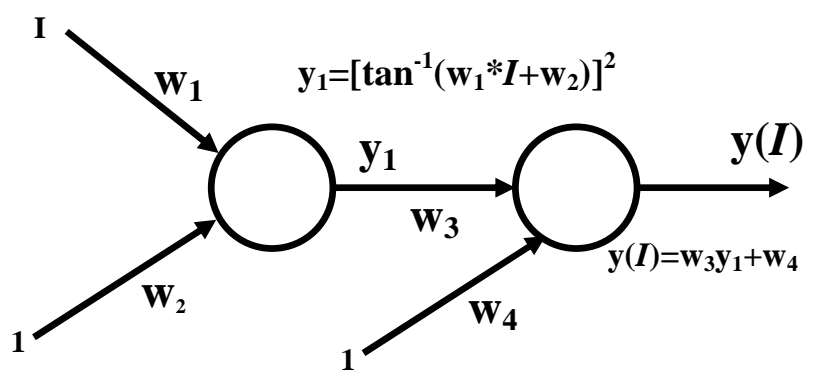

Figure 1: Neural Network tor fitting Non-Linearity

Table 2: Parameters of the RGB non-linearity

\begin{tabular}{|c|c|c|c|c|c|c|}
\hline Col. & $\mathrm{w}_{1}$ & $\mathrm{w}_{2}$ & $\mathrm{w}_{3}$ & $\mathrm{w}_{4}$ & $\max (\mathrm{y}-\mathrm{d})$ & $\mathrm{MSE}$ \\
\hline Red & 89.13 & 210.07 & 9288.88 & -22781.54 & 0.43 & 0.056 \\
\hline Green & 46.74 & 149.5 & 9334.13 & -22836.44 & 0.4 & 0.037 \\
\hline Blue & 41.59 & 143.55 & 9339.37 & -22843.18 & 0.52 & 0.48 \\
\hline
\end{tabular}

Note that all the parameters w1, w2, w3 and w4 are computed using the back-propagation algorithm. Using these parameters the three curves have been plotted with the intensity using log scale on the $\mathrm{x}$ - axis and the just noticeable differences on $\mathrm{y}$-axis in figure 2 .

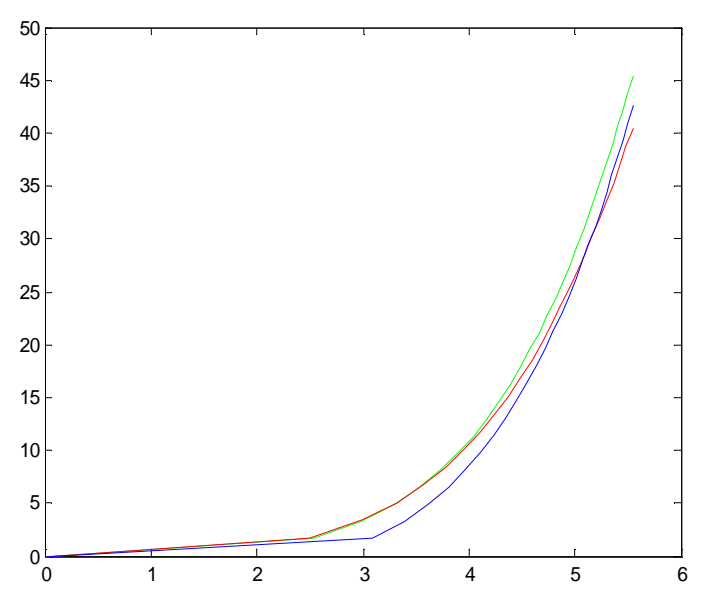

Figure 2: Responses of typical R, G and B retinal receptors

\section{RESULTS ON REAL LIFE COLOR IMAGES}

For verifying this approach of non-linear, non-uniform sampling of color images, based on these parameters, the quantization levels on each axis has been computed and every pixel color in the image has been reduced to its nearest lower quantization level. Thus every image selected for further experimentation has been sampled according to the new sampling approach. For our work, a set of real life color images has been selected and these are shown in figure 3 and figure 4 . The images have been selected in such a way that a lot of variations are observed amongst them. Figure 3 (a) and figure 4 (a) show the respective sampled color images using this approach. It may be noted that it is hardly possible to mark any difference between the original images and the sampled images indicating that the visual quality of each image has been maintained. Other applications of this work include printing color images on white background using optimum ink and absolute color vision testing.

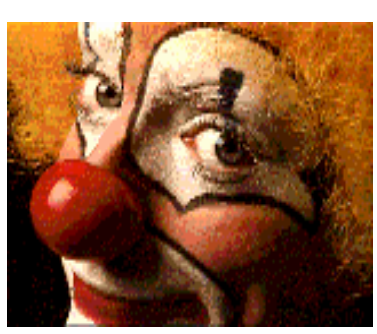

Figure 3 Clown

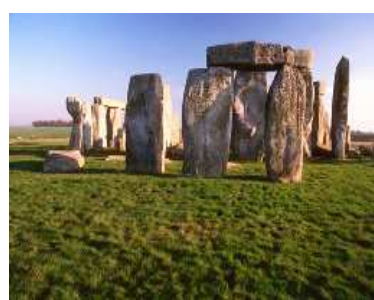

Figure 4 Stone

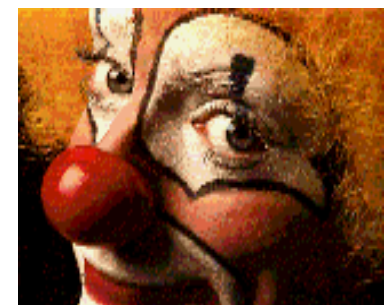

Figure 3(a) Sampled

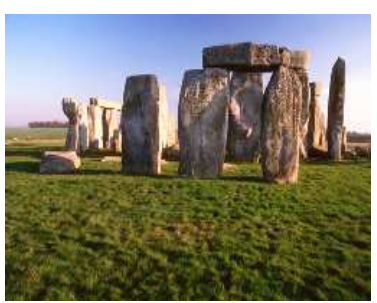

Figure 4(a) Sampled

\section{SUMMARY}

Thus in this paper the technique of non-linear color image sampling in RGB space under limitations of human vision can be used in number of application of machine vision Some color image sampling and printing results are provided for the sake of completeness. For the non-linear sampling of the RGB space a parametric nonlinear model of Red, Green and Blue human color vision has been worked out based on the Buchsbaum's [7] model of human vision and some physiological parameters of human eye and vision.

To estimate the parameters of human vision, responses of color normal human eyes were noted from various age group observers and an average set of response was fit into the non-linearity equation for human vision. Based on the RGB color vision parametric models, it was decided how many colors a normal human eye should discriminate on the same lines as the just noticeable color difference. The same information can be used for machine vision applications.

\section{REFERENCES}

[1] Gaurav Sharma, "Digital color imaging", IEEE Transactions on Image Processing, Vol. 6, No.7, July1997, pp.901-932.

[2] J. Trussell and Manish S. Kulkarni, "Sampling and processing of color signals", IEEE Transactions on Image Processing, Vol. 5, No.4, April1996, pp.677-681. 
[3] Jean-Pierre Braquelaire and Luc Brun, "Comparison and optimization of methods of color image quantization", IEEE Transactions on Image Processing, Vol.6, No.7, July1997, pp.1048-1051.

[4] Young-Chang Chang and John F. Reid, "RGB calibration for color image analysis in machine vision", IEEE Transactions on Image Processing, Vol. 5, No.10, October 1996, pp.1414-1422.

[5] Sang Ho Park, Il Dong Yun and Sang Uk Lee, "Color image segmentation based on 3-D clustering : morphological approach", Pergamon Pattern Recognition, Vol.44, No.8,1998,pp.1061-1076.

[6] Fang-Hsuan Cheng, Wen-Hsing Hsu and Te-Wei Chen, "Recovering colors in an image with chromatic illuminant", IEEE Transactions on Image Processing, Vol. 7, No.11, November1998, pp.1524-1533.

[7] Gershon Buchsbaum, "An analytical derivation of visual nonlinearity”, IEEE Transactions on Biomedical Engg., Vol. BME-27,No.5, May1980, pp.237-242.

[8] Gershon Buchsbaum, "The retina as a two-dimensional detector array in the context of color vision theories and signal detection theory", Proceedings of the IEEE, Vol. 69, No.7, July1981, pp.772-786.

[9] A.C.Guyton, "A text book of medical Physiology", W.B.Saunders company, Philadelphia,1976, pp.784-824.

[10] William Hart Jr. and Nigel W. Daw, "Adler's Physiology of vision", Edited by Robert Moses, Jaypee brothers, U.S.A,1980,pp.351-353 \& 569-582.

[11] E. Boldrin, R.Schettini , "RGB calibration for color image analysis in machine vision", IEEE Transactions on Image Processing, Vol. 5, No.10, October1998, pp.1714-1722.

[12] A.K. Ray, K.M. Bhurchandi, "An analytical approach for sampling the RGB color space considering limitation of human vision and its application to color image analysis", Proceedings of ICVGIP 2000, Banglore, pp.44-49.

[13] Edward Chang, Chen Li, Beitao Li,"Toward perception based image retrieval" proceedings of IEEE workshop on Content-based Access of Image and Video Libraries. 2000.

[14] Caron, Y. Vincent, N, "Compressed Image Quality Evaluation using Power Law Models" Proceedings of Pattern Recognition, ICPR 2006, Vol 3, pp. $657-660$. 